\title{
Growth modes of platinum overlayers resulting from square wave perturbing potential treatments of different symmetries
}

\author{
A. Visintin, J.C. Canullo, W.E. Triaca and A.J. Arvia \\ Instituto de Investigaciones Fisicoquimicas Teóricas y Aplicadas (INIFTA), Facultad de Ciencias Exactas, \\ Universidad Nacional de La Plata, Casilla de Correo 16, Sucursal 4, (1900) La Plata (Argentina)
}

(Received 3 January 1989; in revised form 30 March 1989)

\begin{abstract}
The application of square-wave potential treatments to platinum electrodes in acid solution under suitable conditions produces remarkable changes in both the roughness and crystallographic orientation of the electrode surface. The influence of the symmetry of the perturbing potential at different frequencies on the growth mode of the platinum overlayers has been studied. The overall effect is discussed in terms of the relative contribution of metal electrodissolution/electrodeposition and oxide layer electroformation/electroreduction processes.
\end{abstract}

\section{INTRODUCTION}

The application of periodic perturbing potentials to several fcc metals can produce a particular type of growth mode of the electroreduced metal overlayer accompanied by the development of a preferred crystallographic orientation and a simultaneous increase in the electrode roughness under controlled conditions. The determining parameters of the overall effect are the upper $\left(E_{\mathrm{u}}\right)$ and lower $\left(E_{1}\right)$ potential limits, the frequency $(f)$ and the symmetry of the perturbing signal. The latter can be characterized by the ratio of the corresponding half-periods, $\left(\tau_{u}\right.$ and $\tau_{1}$ ), i.e., the real times associated with the anodic reactions at $E_{\mathrm{u}}$ and the cathodic reactions at $E_{1}$, respectively. According to the model advanced recently to account for the mechanism of the electrochemical facetting and roughening development [1-5], the values of $\tau_{u}$ and $\tau_{1}$ play an important role in defining the characteristics of the diffusional boundary layers related to the anodic and the cathodic reactions at the metal/solution interface [5-7] and they also influence the surface processes themselves, including metal adatom surface diffusion, particularly during the cathodic half cycle. Despite the number of contributions made on the subject in recent years, a more extensive investigation of the influence of the symmetry of the 
perturbing potential on the concurrent development of preferred crystallographic orientation and change in electrode roughness is required. This paper is devoted to a study of the growth modes of Pt overlayers resulting from square wave perturbing potential treatments of different symmetries, and for this purpose, special attention is paid to Pt in acid solution because as far as this matter is concerned, this metal has been the most extensively investigated so far.

\section{EXPERIMENTAL}

The working electrodes consisted of polyfaceted single crystal (sc) Pt microspheres grown by heating at the end of Pt wires, following the procedure described elsewhere [8]. The geometric areas of these electrodes were comprised between 0.01 and $0.04 \mathrm{~cm}^{2}$. The working electrode was placed in the electrochemical cell containing $1 \mathrm{M} \mathrm{H}_{2} \mathrm{SO}_{4}$ at $25^{\circ} \mathrm{C}$ and its potential was measured against a reversible hydrogen electrode (RHE) in the same solution. All potentials in the text are referred to the RHE.

The electrochemical experiments comprised the following stages:

(i) Electrode pretreatment involving repetitive triangular potential cycling at 0.1 $\mathrm{V} / \mathrm{s}$ between 0.05 and $1.50 \mathrm{~V}$ until a stabilized voltammogram (blank) was attained. SEM micrographs of the pretreated electrode were obtained for further comparison.

(ii) The pretreated electrode was subsequently subjected to a repetitive square wave potential scanning (RSWPS) between $E_{1}=0.05 \mathrm{~V}$ and $E_{\mathrm{u}}=1.50 \mathrm{~V}$ at a frequency, $f$, during a certain time $t$. For a preset $f$ the values of $\tau_{u}$ and $\tau_{1}$ were also varied systematically, covering the following $\tau_{\mathcal{L}} / \tau_{1}$ ratio range: $4 \times 10^{-3} \leqslant$ $\left(\tau_{u} / \tau_{1}\right) \leqslant 250$.

(iii) The voltammogram of the treated electrode was recorded again under the same conditions indicated in (i). SEM micrographs of the treated electrode were then obtained systematically.

The following criteria were followed to estimate the development of preferred crystallographic orientation (pco) and the change in the electrode roughness. According to recent work on the electrosorption of $\mathbf{H}$ on Pt single crystals in acids, the main voltammetric peak at lower potentials $\left(h_{1}\right)$ (weakly bound $\mathbf{H}$-adatoms), which was originally assigned to the $\mathrm{H}$-adatom- $\mathrm{Pt}$ (111) site interaction $[9,10]$, corresponds to H-electrosorption on disturbed $\mathrm{Pt}$ (111) surfaces with a larger number of $\mathrm{Pt}(110)$ sites [11,12], whereas the main voltammetric peak at higher potentials $\left(h_{2}\right)$ (strongly bound $\mathrm{H}$-adatoms) represents the $\mathrm{H}$-adatom-Pt $(100)$ site interaction [11,13-16]. Accordingly, the height ratio of these two peaks, $h_{2} / h_{1}$, can be taken arbitrarily to follow the degree of pco achieved throughout the treatment described in (ii). Thus, for the initial polyfaceted sc Pt, the average $h_{2} / h_{1}$ ratio was ca. 0.64. Analogously, the relative increase in active surface area $(R)$ of the resulting surface can also be determined voltammetrically through either the corresponding $\mathrm{H}$-adatom monolayer charge or the electroreduction charge of the $\mathrm{O}$-monolayer, before and after the application of the RSWPS treatment. Further details of the cell 
design, cleaning procedures, electronic circuit and other experimental features are given in previous publications $[5,17]$.

\section{RESULTS}

General behaviour of Pt electrodes after RSWPS treatments in the $0.1 \leqslant f \leqslant 5.6 \mathrm{kHz}$ range

The influence of the symmetry of the square wave perturbing potential on both the $h_{2} / h_{1}$ ratio and the value of $R$, after $1 \mathrm{~h}$ RSWPS from $E_{1}=0.05 \mathrm{~V}$ to $E_{\mathrm{u}}=1.50$ $\mathrm{V}$, is depicted in Fig. 1. At any $f$ the range of $\tau_{\mathrm{u}} / \tau_{1}$ related to the peaked value of $R$ does not coincide with the range of $\tau_{\mathrm{u}} / \tau_{1}$ where the largest increase in the $h_{2} / h_{1}$ ratio is observed. For the peaked value of $R$, the corresponding $\log \tau_{\mathrm{u}} / \tau_{1}$ ratio decreases as $f$ increases. Otherwise, for $f>0.1 \mathrm{kHz}$, the $h_{2} / h_{1}$ ratio exhibits a bell-shaped dependence on $\log \left(\tau_{u} / \tau_{1}\right)$, the maximum value for the $h_{2} / h_{1}$ ratio corresponding to the symmetric RSWPS, i.e. $\log \tau_{\mathrm{u}} / \tau_{1}=0$. At $f=0.1 \mathrm{kHz}$ two peaked values of the $h_{2} / h_{1}$ ratio appear at $\log \tau_{\mathrm{u}} / \tau_{1}=-1.52$ and $\log \tau_{\mathrm{u}} / \tau_{1}=1.28$.
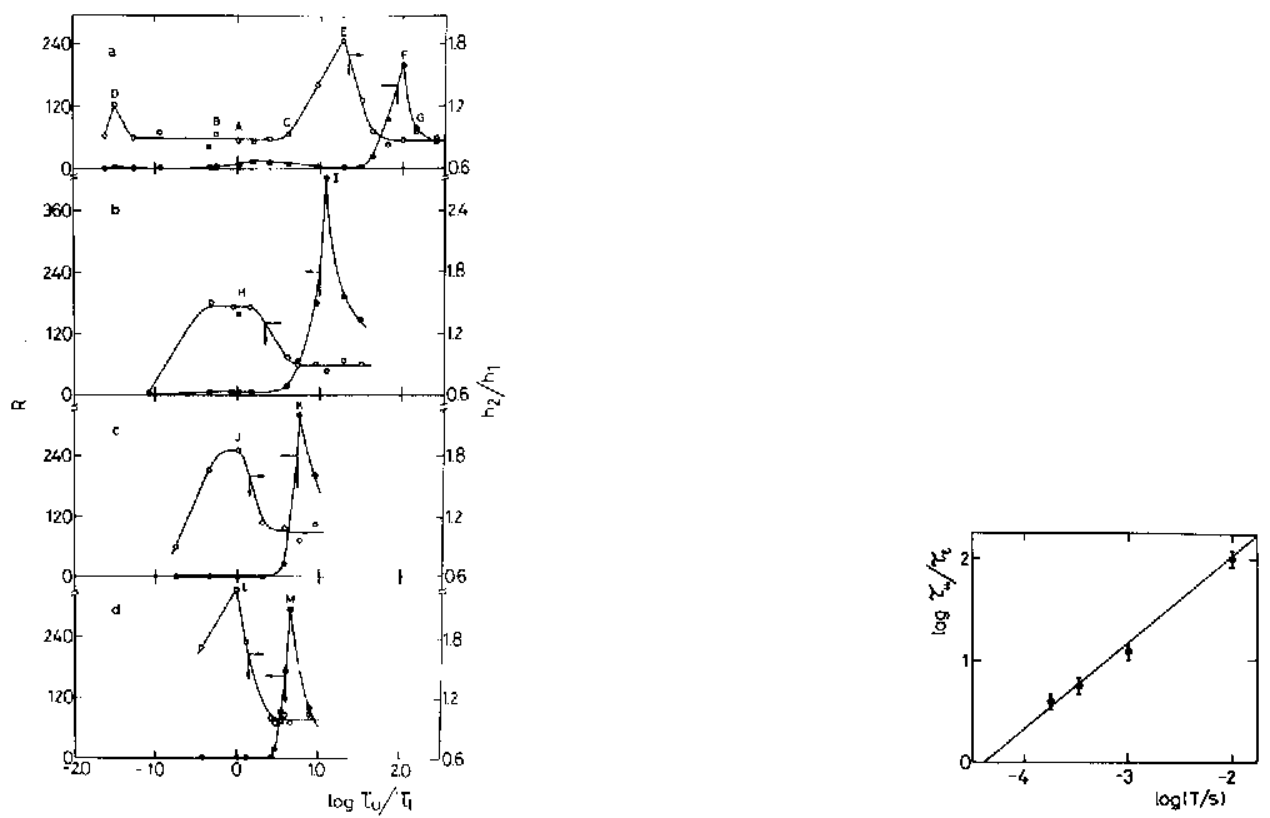

Fig. 1. Dependence of $R$ and $h_{2} / h_{1}$ on $\log \tau_{u} / \tau_{1}$ at different $f$ derived from stabilized voltammograms run at $0.1 \mathrm{~V} / \mathrm{s}$ between 0.05 and $0.60 \mathrm{~V}$ in $1 \mathrm{M} \mathrm{H}_{2} \mathrm{SO}_{4}, 25^{\circ} \mathrm{C}$, after $1 \mathrm{~h}$ RSWPS treatment $\left(E_{1}=0.05 . \mathrm{V}\right.$, $E_{\mathrm{u}}=1.50 \mathrm{~V}$, $f:$ (a) 0.1 ; (b) 1 ; (c) 3 , (d) $5.6 \mathrm{kHz}$.

Fig. 2. Dependence of $\tau_{u} / \tau_{l}$ ratios corresponding to the peaked values of $R$ on the period $(T)$ of the perturbing potential. 
As $f$ increases the region where changes can be observed in the values of both $h_{2} / h_{1}$ ratio and $R$ become narrower.

The $\tau_{\mathrm{u}} / \tau_{1}$ ratio values corresponding to the peaked values of $R$ at different $f$ can be plotted as $\log \tau_{\mathrm{u}} / \tau_{1}$ vs. $\log T$ (Fig. 2). This plot correlates the $\tau_{\mathrm{u}} / \tau_{1}$ ratio directly related to the symmetry of the RSWPS and $T$, the time associated with a single complete oxidation-reduction cycle.

Characteristics of platinum overlayers resulting from RSWPS at $f=0.1 \mathrm{kHz}$

The morphology of the electroreduced metal overlayer as seen through the SEM micrographs becomes strongly dependent on the entire operating conditions. Thus,
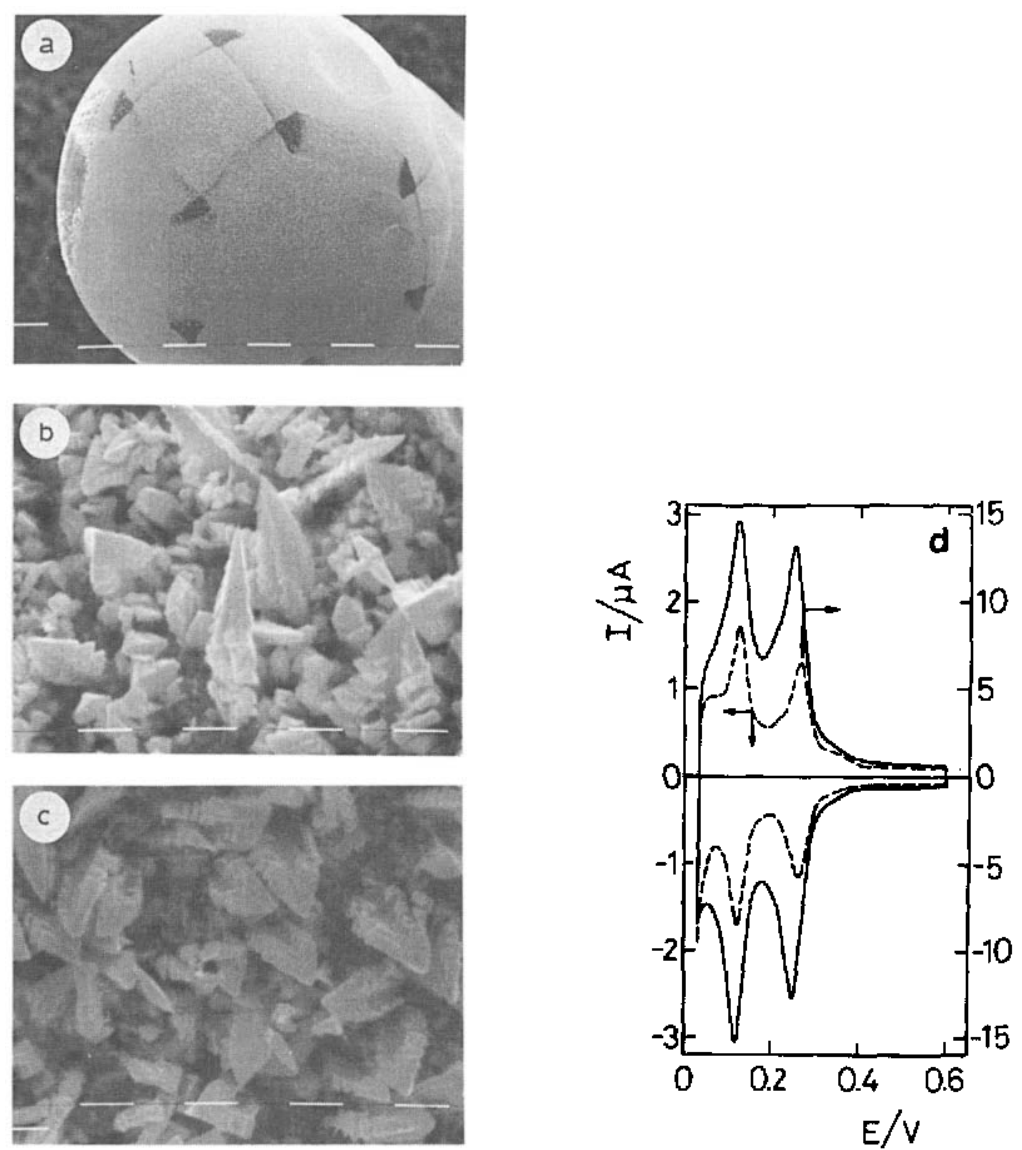

Fig. 3. SEM micrographs and stabilized voltammograms nun at $0.1 \mathrm{~V} / \mathrm{s}$ in $1 \mathrm{M} \mathrm{H}_{2} \mathrm{SO}_{4}, 25^{\circ} \mathrm{C}$, after $1 \mathrm{~h}$ RSWPS treatment $\left(E_{1}=0.05 \mathrm{~V}, E_{\mathrm{u}}=1.50 \mathrm{~V}, f=0.1 \mathrm{kHz}, \tau_{\mathrm{u}} / \tau_{1}=1\right)$. (a) SEM micrograph of the treated surface, scale $100 \mu \mathrm{m}$. (b) SEM micrograph of the region around the [100] crystallographic pole, scale 1 $\mu \mathrm{m}$. (c) SEM micrograph of the region around the [111] crystallographic pole, scale $1 \mu \mathrm{m}$. (d) (- Voltammogram run between 0.05 and $0.60 \mathrm{~V} ;\left(--C_{-}\right)$untreated polyfaceted sc platinum sphere. 
the micrographs resulting at point $A$ in Fig. la show that the electrode surface is uniformly covered by a metal overlayer of dendritic structure (Figs. 3a-c), except for a few symmetrically distributed small areas presumably corresponding to the [310] pole family (Fig. 3a). Furthermore, a peculiar geometry with a regular symmetry originating around the [100] and [111] crystallographic poles can be
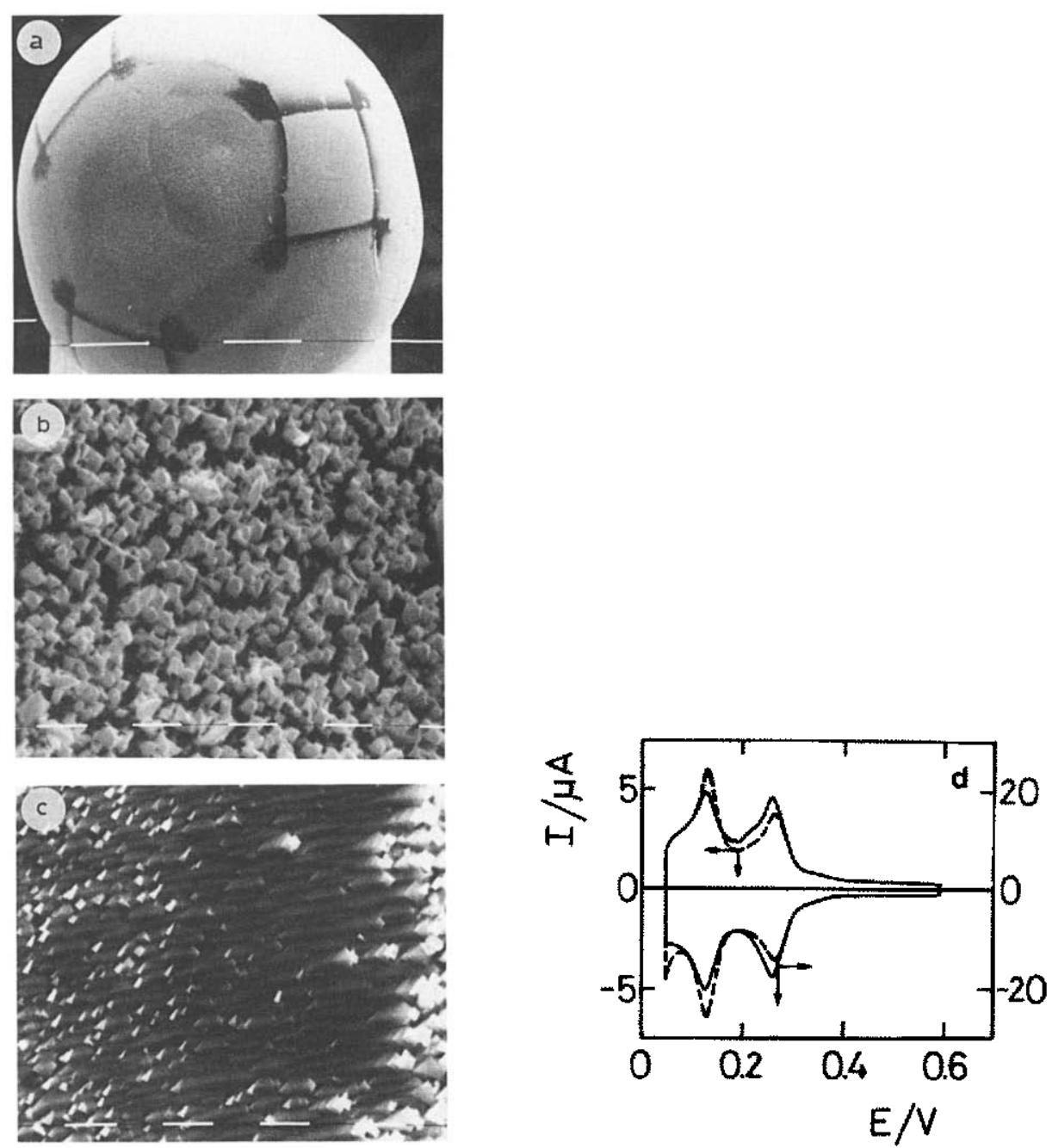

Fig. 4. SEM micrographs and stabilized voltammograms ran at $0.1 \mathrm{~V} / \mathrm{s}$ in $1 \mathrm{M} \mathrm{H}_{2} \mathrm{SO}_{4}, 25^{\circ} \mathrm{C}$, after $1 \mathrm{~h}$ RSWPS treatment $\left(E_{\mathrm{l}}=0.05 \mathrm{~V}, E_{\mathrm{u}}=1.50 \mathrm{~V}, f=0.1 \mathrm{kHz}, \tau_{\mathrm{u}} / \tau_{1}=0.54\right)$. (a) SEM micrograph of the treated surface, scale $100 \mu \mathrm{m}$. (b) SEM micrograph of the region around the [100] crystallographic pole, scale $1 \mu \mathrm{m}$. (c) SEM micrograph half way between the [310] crystallographic poles, scale $1 \mu \mathrm{m}$. (d) (m- ) Voltammogram run between 0.05 and $0.60 \mathrm{~V} ;(--\rightarrow)$ untreated polyfaceted sc platinum sphere. 
distinguished. The voltammetric response of the electroreduced Pt overlayer (Fig. 3d) shows a significant increase in the voltammetric charge related to the $\mathrm{H}$-electroadsorption/electrodesorption peaks $(R=11)$ but the relative height of the voltammetric peaks $\left(h_{2} / h_{1}=0.89\right)$ is modified only slightly as compared to the blank.

The SEM micrographs obtained at point $B$ again show a regular crystallographic pattern for the $\mathrm{Pt}$ overlayer (Fig. 4a). However, at large magnifications polyhedric and stepped structures can be observed in different electrode regions (Figs. 4b,c). The voltammogram of this electrode (Fig. 4d) shows a minor increase in $R$ $(R=4.4)$ and a slight trend to develop (100)-type pco $\left(h_{2} / h_{1}=0.97\right)$.

The $\mathrm{Pt}$ overlayers resulting at point $\mathrm{C}$ exhibit again a predominant dendritic structure, although pyramidal formations can also been distinguished. The corresponding voltammograms show in this case a slight increase in $R(R=3.3)$ and a clear trend to develop the (100)-type pco $\left(h_{2} / h_{1}=1.04\right)$.
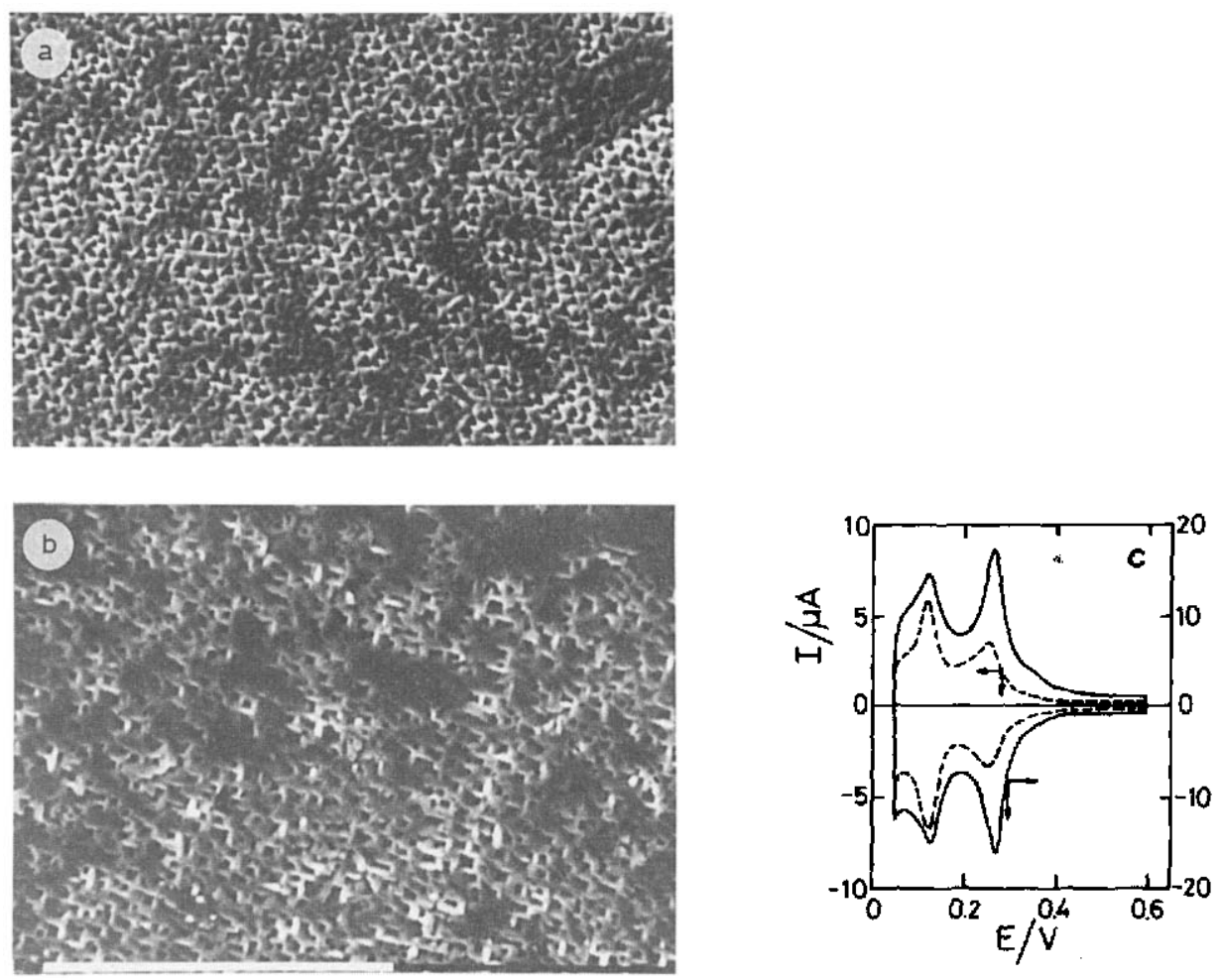

Fig. 5. SEM micrographs and stabilized voltammograms run at $0.1 \mathrm{~V} / \mathrm{s}$ in $1 \mathrm{M} \mathrm{H}_{2} \mathrm{SO}_{4}, 25^{\circ} \mathrm{C}_{\text {, }}$ after $1 \mathrm{~h}$ RSWPS treatment $\left(E_{1}=0.05 \mathrm{~V}, E_{\mathrm{u}}=1.50 \mathrm{~V}, f=0.1 \mathrm{kHz}, \tau_{\mathrm{u}} / r_{1}=0.03\right)$. (a) SEM micrograph of the region around the [111] crystallographic pole, scale $10 \mu \mathrm{m}$. (b) SEM micrograph of the region around the [100] crystallographic pole, scale $10 \mu \mathrm{m}$. (c) (_-) Voltammogram run between 0.05 and $0.60 \mathrm{~V}$; (- - ) untreated polyfaceted sc platinum sphere. 

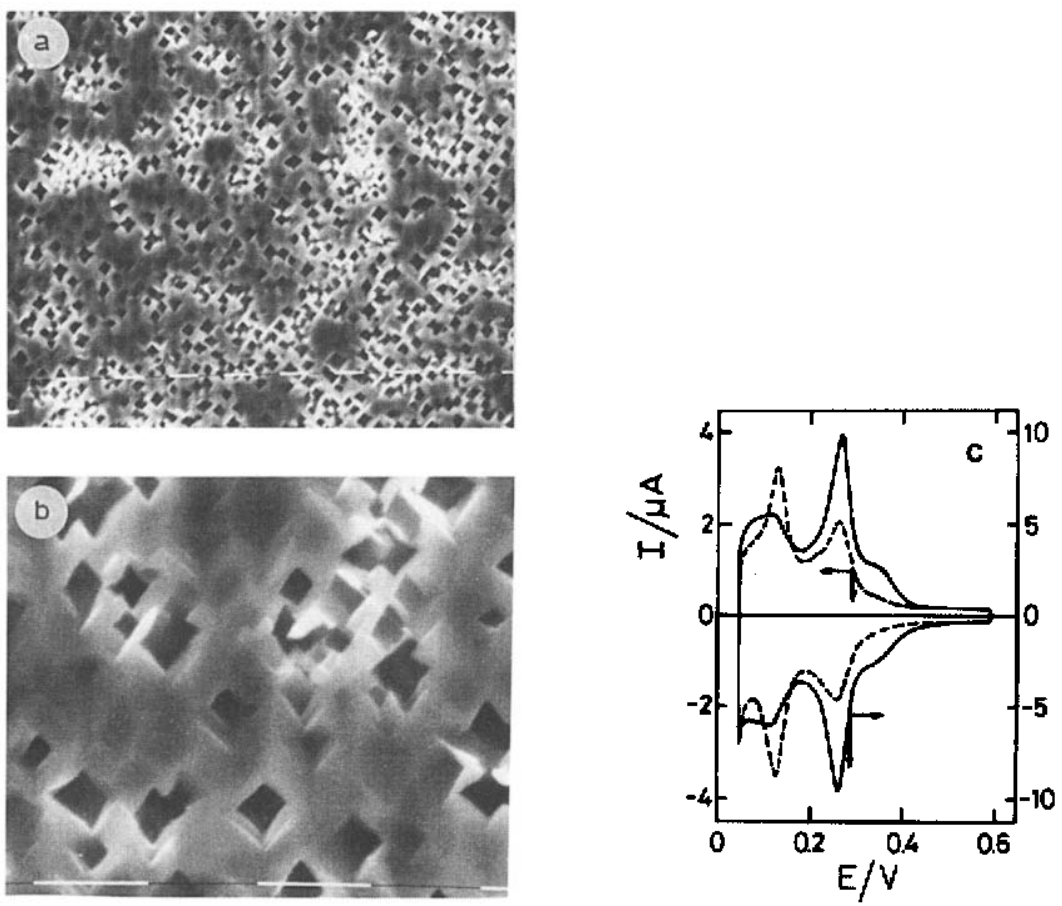

Fig. 6. SEM micrographs and stabilized voltammograms run at $0.1 \mathrm{~V} / \mathrm{s}$ in $1 \mathrm{M} \mathrm{H}_{2} \mathrm{SO}_{4}, 25^{\circ} \mathrm{C}$, after $1 \mathrm{~h}$ RSWPS treatment $\left(E_{1}=0.05 \mathrm{~V}, E_{\mathrm{u}}=1.50 \mathrm{~V}, f=0.1 \mathrm{kHz}, \tau_{\mathrm{u}} / \tau_{\mathrm{t}}=19\right)$ ). (a,b) SEM micrographs of the region around the [100] crystallographic pole, scale $1 \mu \mathrm{m}$. (c) (- Voltammogram run between 0.05 and $0.60 \mathrm{~V} ;(-\ldots+)$ untreated polyfaceted sc platinum sphere.

Another quite different topography appears at point $\mathrm{D}$. In this case, no dendrite formation is accomplished (Figs. 5a,b), but the metal overlayer is distributed rather non-uniformly and presents a peculiar geometry at certain well-defined regions. Thus, in the region corresponding to the [111] pole, the metal overlayer results in a regular network of inverted pyramid-shaped units (Fig. 5a), whereas in the [100] pole region it is made of square-shaped units (Fig. $5 \mathrm{~b}$ ). The voltammogram of this Pt surface (Fig. 5c) shows a clear trend to develop (100)-type pco $\left(h_{2} / h_{1}=1.2\right)$ with a minor increase in surface roughness $(R=3.6)$.

The SEM micrographs resulting at point $\mathrm{E}$, that is, at the maximum value of the $h_{2} / h_{1}$ ratio, correspond to a Pt overlayer with a characteristic cubic geometry (Figs. $6 \mathrm{a}, \mathrm{b})$. The corresponding voltammogram (Fig. 6c) shows a net development of (100)-type pco $\left(h_{2} / h_{1}=1.85\right)$ and a minor increase in surface roughness $(R=3.8)$.

On the other hand, the surface topography brought about for the peaked value of $R$ (point F), which corresponds to the application of an asymmetric RSWPS with a $\tau_{\mathrm{u}} / \tau_{1}$ ratio equal to 99 followed by slow electroreduction scans at $0.1 \mathrm{~V} / \mathrm{s}$, involves a Pt overlayer with large patches (Fig. 7a) formed by a rather uniform distribution of small sticking globules of about $0.25 \mu \mathrm{m}$ average diameter (Fig. $7 \mathrm{~b}$ ). This mor- 

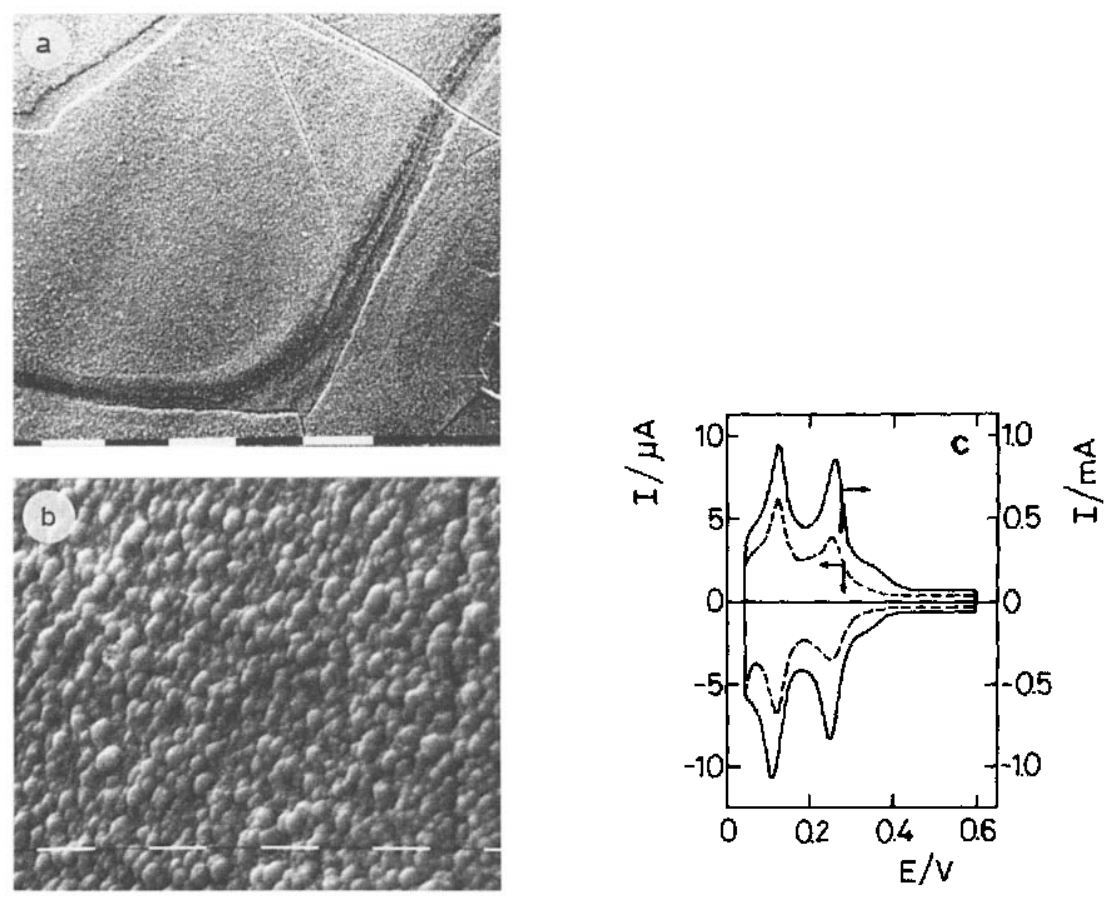

Fig. 7. SEM micrographs and stabilized voltammograms run at $0.1 \mathrm{~V} / \mathrm{s}$ in $1 \mathrm{M} \mathrm{H}_{2} \mathrm{SO}_{4}, 25^{\circ} \mathrm{C}_{1}$ after $1 \mathrm{~h}$ RSWPS treatment $\left(E_{1}=0.05 \mathrm{~V}, E_{\mathrm{u}}=1.50 \mathrm{~V}, f=0.1 \mathrm{kHz}, \tau_{\mathrm{u}} / \tau_{1}=99\right)$. (a,b) SEM micrographs of the treated surface, scale: (a) $10 \mu \mathrm{m}$; (b) $1 \mu \mathrm{m}$. (c) (__ ) Voltammogram run between 0.05 and $0.60 \mathrm{~V}$; (- - - ) untreated polyfaceted sc platinum sphere.

phology is similar to that already described for the electroreduction of hydrous platinum oxide layers accumulated through a RSWPS treatment from 0.05 up to 2.5 $\mathrm{V}$ at a few $\mathrm{kHz}$ [18]. These electrodes furnish $\mathrm{H}$-adatom electroadsorption/electrodesorption voltammograms (Fig. 7c) involving a notable increase in the voltammetric charge $(R=203)$ but without detectable changes in the $h_{2} / h_{1}$ ratio $\left(h_{2} / h_{1}=\right.$ 0.88 ) as compared to the starting polyfaceted sc Pt.

A similar qualitative behaviour results for those $P$ t overlayers produced under the conditions of point $\mathrm{G}$, although in this particular case the increase in voltammetric charge becomes smaller $(R=80)$ than in the preceding case.

Characteristics of the Pt overlayer resulting from RSWPS at $f=1 \mathrm{kHz}$

Typical SEM micrographs and voltammograms of Pt overlayers resulting from the application of RSWPS at $f=1 \mathrm{kHz}$ are seen in Figs. 8 and 9. For the $\tau_{\mathrm{u}} / \tau_{1}$ range corresponding to the maximum values of the $h_{2} / h_{1}$ ratio, e.g., point $\mathrm{H}$, the RSWPS treatment produces $P$ t overlayers with a surprisingly interesting symmetric pattern originating around the [100] and [111] poles (Fig. 8a). The SEM observation of a region around the [100] pole shows faceted crystallites, presumably with (100) 

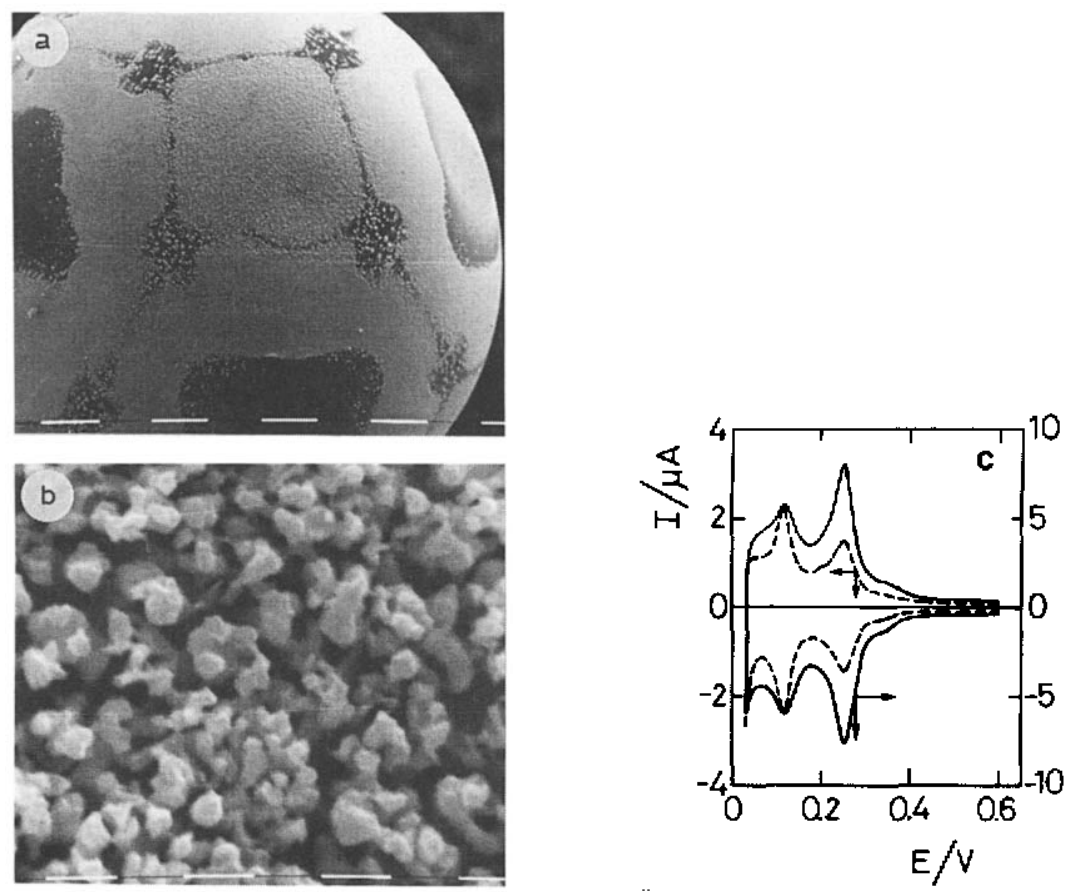

Fig. 8. SEM micrographs and stabilized voltammograms run at $0.1 \mathrm{~V} / \mathrm{s}$ in $1 \mathrm{M} \mathrm{H}_{2} \mathrm{SO}_{4}, 25^{\circ} \mathrm{C}$, after $1 \mathrm{~h}$ RSWPS treatment $\left(E_{1}=0.05 \mathrm{~V}, E_{\mathrm{u}}=1.50 \mathrm{~V}, f=1 \mathrm{kHz}, \tau_{\mathrm{u}} / \tau_{1}=1\right)$. (a) SEM micrograph of the treated surface, scale $100 \mu \mathrm{m}$. (b) SEM micrograph of the region around the [100] crystallographic pole, scale 1 $\mu \mathrm{m}$. (c) (-) Voltammogram run between 0.05 and $0.60 \mathrm{~V} ;(---)$ untreated polyfaceted sc platinum sphere.
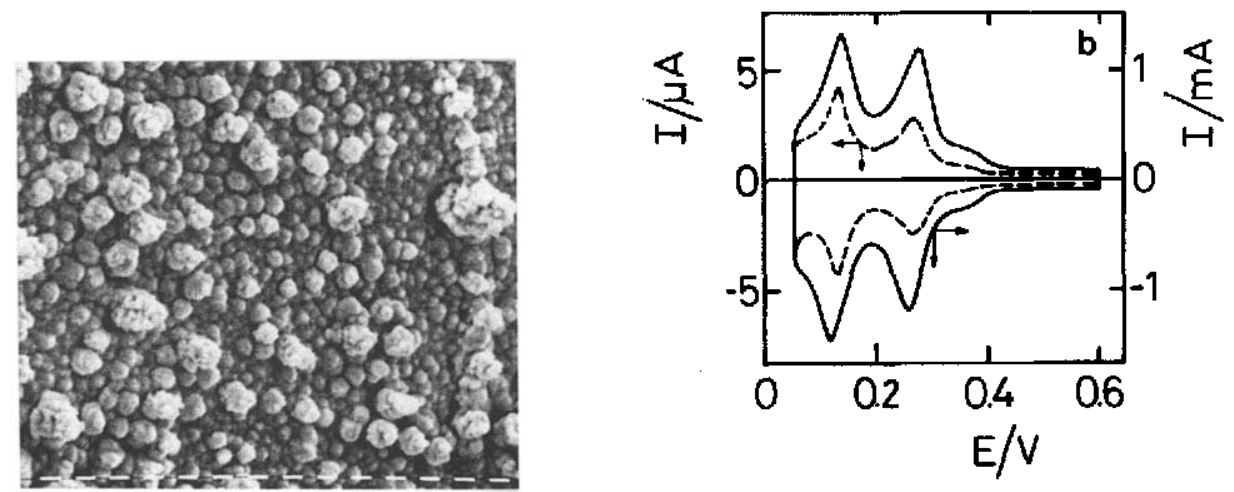

Fig. 9. SEM micrographs and stabilized voltammograms run at $0.1 \mathrm{~V} / \mathrm{s}$ in $1 \mathrm{M} \mathrm{H}_{2} \mathrm{SO}_{4}, 25^{\circ} \mathrm{C}$, after $1 \mathrm{~h}$ RSWPS treatment $\left(E_{1}=0.05 \mathrm{~V}, E_{\mathrm{u}}=1.50 \mathrm{~V}, f=1 \mathrm{kHz}, \tau_{\mathrm{u}} / \tau_{\mathrm{l}}=12\right)$. (a) SEM micrograph of the treated surface, scale $1 \mu \mathrm{m}$. (b) (- Voltammogram run between 0.05 and $0.60 \mathrm{~V}$; ( -- ) untreated polyfaceted sc platinum sphere. 
pco (Fig. 8b), as reflected in the voltammetric results $\left(h_{2} / h_{1}=1.40\right)$ (Fig. 8c). On the other hand, for the conditions of the RSWPS treatment where the maximum value of $R$ is obtained (point $\mathrm{I}$ ) the resulting $\mathrm{Pt}$ overlayer presents a typical cauliflower structure consisting of small and large globules (Fig. 9a) and a stabilized voltammogram exhibiting a dramatic increase in voltammetric charge $(R=422)$ but practically no changes in the $h_{2} / h_{1}$ ratio $\left(h_{2} / h_{1}=0.80\right)$ as compared to the blank (Fig. 9b).

It is interesting to observe, for a symmetric wave, the effect of $E_{\mathrm{u}}$ at $f=1 \mathrm{kHz}$ and $t=1 \mathrm{~h}$ on the entire process in order to establish whether the Pt overlayer results primarily from an oxide layer accumulated during the RSWPS or to some extent from the proper metal electrodissolution/electrodeposition cycles. In these cases, for $1.4 \leqslant E_{\mathrm{u}} \leqslant 1.6 \mathrm{~V}$, the maximum value of $R$ appears for a net predominance of $\tau_{\mathrm{u}}$ over $\tau_{\mathrm{l}}$. Thus, as $E_{\mathrm{u}}$ increases, the $\tau_{\mathrm{u}} / \tau_{1}$ ratio required for achieving the maximum value of $R$ decreases from 21 for $E_{\mathrm{u}}=1.4 \mathrm{~V}$ to 11 for $E_{\mathrm{u}}=1.50 \mathrm{~V}$ and to 9 for $E_{\mathrm{u}}=1.6 \mathrm{~V}$.

Characteristics of Pt overlayers resulting from RSWPS at $f=3 \mathrm{kHz}$

After symmetric RSWPS treatment at $f=3 \mathrm{kHz}$, that is, under the conditions corresponding to point $\mathbf{J}$ in Fig. 1c, the treated Pt surface shows a crystallographic pattern compatible with the (100) pco (Fig. 10a). Furthermore, in the region around the [111] pole, a highly faceted surface exhibiting a cubic geometry can be observed (Fig. 10b), whereas near to the [100] pole region small corrugations are clearly seen (Fig. 10c). Accordingly, the voltammogram of this Pt surface (Fig. 10d) shows pratically no increase in surface roughness $(R=1.36)$ and a large degree of development of the (100)-type pco $\left(h_{2} / h_{1}=1.4\right)$.

For the operating conditions where the maximum value of $R$ is accomplished (point $\mathrm{K}$ ), $\mathrm{Pt}$ overlayers exhibiting again a typical cauliflower structure are produced. The voltammetric response in this case also shows a large increase in surface roughness $\left(R=320\right.$ ), and slight changes in the $h_{2} / h_{1}$ ratio as compared to the blank.

Characteristics of Pt overlayers resulting from $R S W P S$ at $f=5.6 \mathrm{kHz}$

As $f$ is increased up to $f=5.6 \mathrm{kHz}$, the maximum values of $R$ and the $h_{2} / h_{1}$ ratio are closer as $\tau_{u} / \tau_{1} \rightarrow 1$. After applying a symmetric RSWPS, that is, under conditions corresponding to point $\mathrm{L}$, one can see the characteristic fourfold macroscopic symmetry around the flat [100] poles (Fig. 11a). Moreover, in the region located between the [100] and [110] poles, typical macrosteps are produced (Fig. $11 \mathrm{~b}$ ), whereas in the region located between the [111] and [100] poles a highly kinked surface results (Fig. 11c). In this case, the voltammogram of the treated $\mathbf{P t}$ surface (Fig. 11d) shows no increase in surface roughness $(R=1)$, and it approaches the characteristics reported in the literature for either Pt (100) sc surfaces or Pt sc stepped surfaces with $(100)$ narrow terraces under comparable conditions $[13,14,19,20]$. 

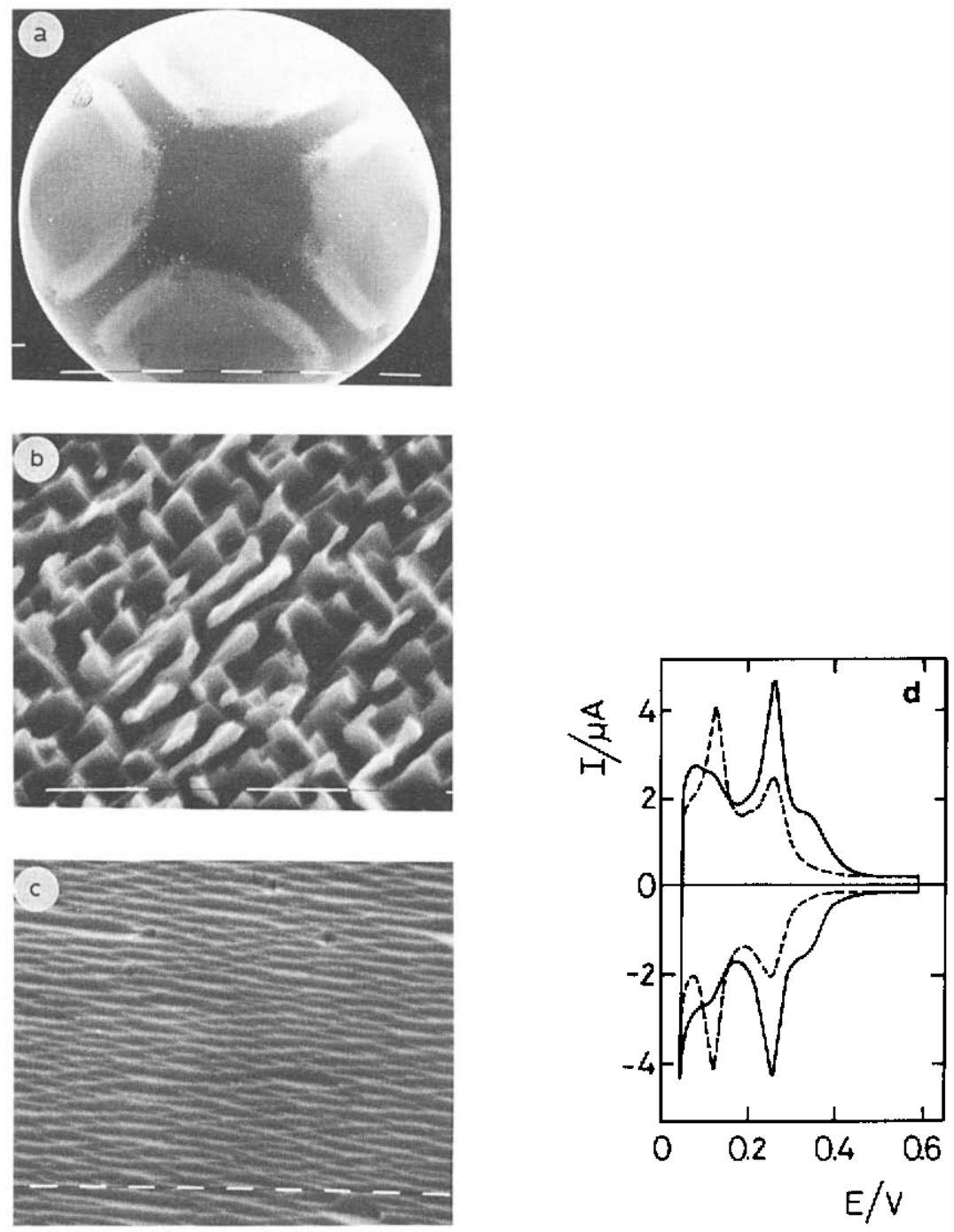

Fig. 10. SEM micrographs and stabilized voltammograms run at $0.1 \mathrm{~V} / \mathrm{s}$ in $1 \mathrm{M} \mathrm{H}_{2} \mathrm{SO}_{4}, 25^{\circ} \mathrm{C}$, after $1 \mathrm{~h}$ RSWPS treatment $\left(E_{1}=0.05 \mathrm{~V}, E_{\mathrm{u}}=1.50 \mathrm{~V}, f=3 \mathrm{kHz}, \tau_{\mathrm{v}} / \tau_{1}=1\right.$ ). (a) $S E M$ micrograph of the treated surface, scale $100 \mu \mathrm{m}$. (b) SEM micrograph of the region around the [111] crystallographic pole, scale 1 $\mu \mathrm{m}$. (c) SEM micrograph of the region around the [100] crystallographic pole, scale $1 \mu \mathrm{m}$. (d) (Voltammogram run between 0.05 and $0.60 \mathrm{~V} ;(\ldots-\infty)$ untreated polyfaceted sc platinum sphere.

On the other hand, for the conditions of the RSWPS treatment where the peaked value of $R$ is obtained (point $\mathrm{M}$ ), the $\mathrm{Pt}$ overlayer presents a structure similar to that already described for points $F, I$ and $K$ and a voltammetric response showing 

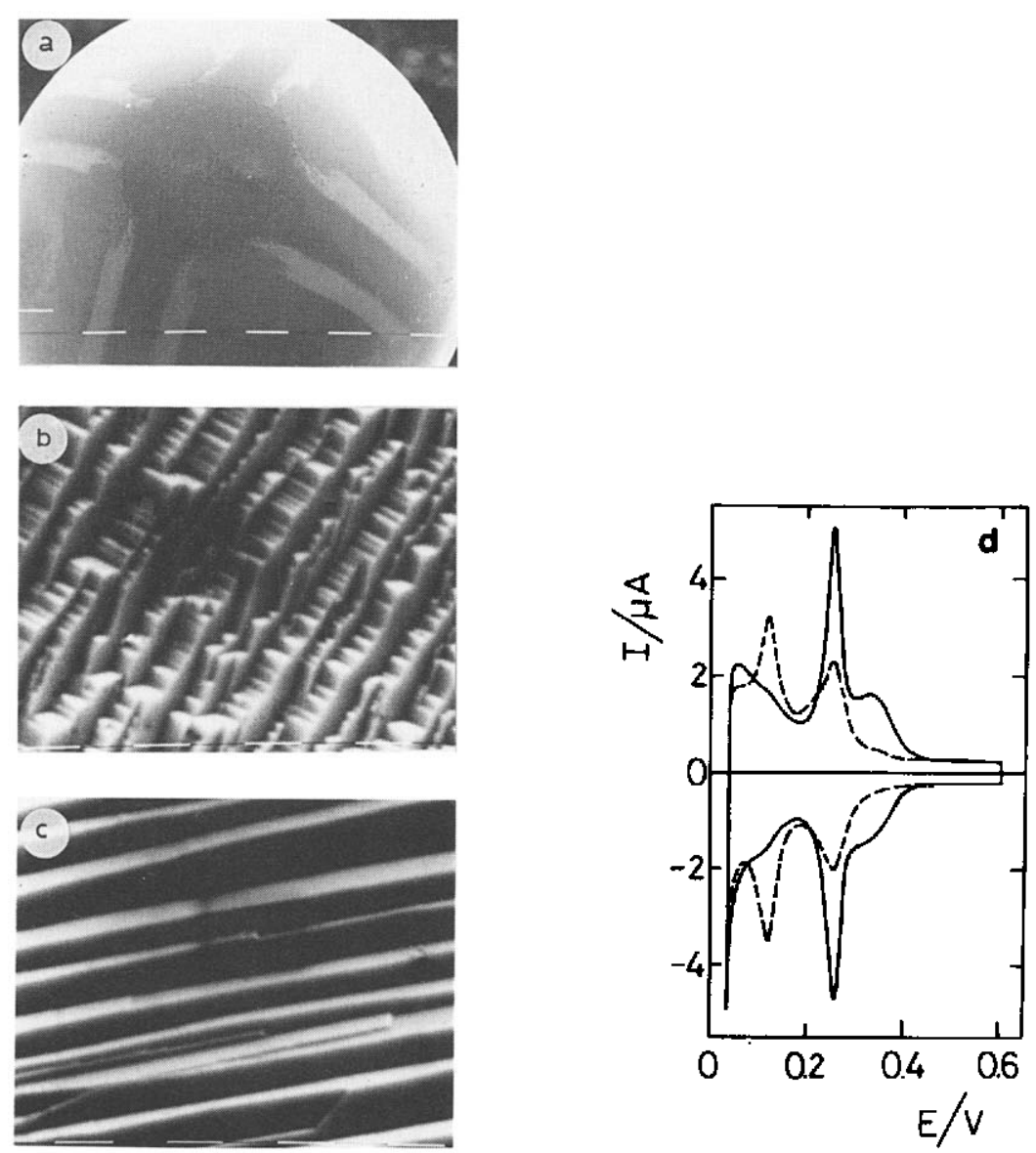

Fig. 11. SEM micrographs and stabilized voltammograms run at $0.1 \mathrm{~V} / \mathrm{s}$ in $1 \mathrm{MH}_{2} \mathrm{SO}_{4}, 25^{\circ} \mathrm{C}$, after $1 \mathrm{~h}$ RSWPS treatment $\left(E_{1}=0.05 \mathrm{~V}, E_{\mathrm{u}}=1.50 \mathrm{~V}, f=5.6 \mathrm{kHz}, \tau_{u} / \tau_{1}=1\right)$. (a) SEM micrograph of the treated surface, scale $100 \mu \mathrm{m}$. (b) SEM micrograph of the region located between the [110] and [100] crystallographic poles, scale $1 \mu \mathrm{m}$. (c) SEM micrograph of the region located between the [111] and [100] crystallographic poles, scale $1 \mu \mathrm{m}$. (d) (- Voltammogram run between 0.05 and $0.60 \mathrm{~V}$; $(---)$ untreated polyfaceted sc platinum sphere.

again a remarkable increase in surface roughness $(R=278)$ and practically no changes in the $h_{2} / h_{1}$ ratio as compared to the blank.

\section{DISCUSSION}

The application of the square wave potential treatment to a Pt electrode under suitable conditions for producing oxidation-reduction cycles (ORC), results in remarkable changes in both the roughness and crystallographic orientation of the electrode surface. The ORC can be related to metal electrodissolution/elec- 
trodeposition and/or to oxide layer electroformation/electroreduction processes, the former being responsible to a large extent for the electrochemical faceting effect with development of preferred crystallographic orientation, whereas the latter concerns mainly the metal surface roughening. The predominance of one or the other type of reaction depends on the values of $E_{\mathrm{u}}$ and $E_{1}, f$ and $\tau_{\mathrm{u}} / \tau_{1}$. For a constant set of $E_{\mathrm{u}}$ and $E_{1}$, as seen in Fig. 1, there is a considerable influence of the RSWPS symmetry on the resulting metal surface characteristics. As a first approximation, a prediction of the feasible electrochemical processes can be derived cautiously from thermodynamics, since most of the runs were made under relatively high frequency treatments, considering the redox couples involving oxidized and reduced metal species. Therefore, when $E_{\mathrm{u}}$ is comprised between 1.40 and $1.60 \mathrm{~V}$, the thermodynamic potentials of the $\mathrm{Pt}^{2+} / \mathrm{Pt}$ and platinum oxide/ $\mathrm{Pt}$ redox couples are exceeded [21], as the corresponding values are:

$$
\begin{array}{ll}
\mathrm{Pt}^{2+}+2 \mathrm{e}^{-}=\mathrm{Pt} & E^{\circ}=1.19 \mathrm{~V} \\
\mathrm{Pt}(\mathrm{OH})+\mathrm{H}^{+}+\mathrm{e}^{-}=\mathrm{Pt}+\mathrm{H}_{2} \mathrm{O} & E^{\circ}=0.85 \mathrm{~V} \\
\mathrm{PtO}+2 \mathrm{H}^{+}+2 \mathrm{e}^{-}=\mathrm{Pt}+\mathrm{H}_{2} \mathrm{O}, & E^{\circ}=0.98 \mathrm{~V} \\
\mathrm{PtO}_{2}+2 \mathrm{H}^{+}+2 \mathrm{e}^{-}=\mathrm{PtO}+\mathrm{H}_{2} \mathrm{O}, & E^{\circ}=1.045 \mathrm{~V}
\end{array}
$$

Hence, platinum oxides and soluble $\mathrm{Pt}^{2+}$ species can, in principle, be formed at $E_{\mathrm{u}}$. However, when symmetric RSWPS are used at $f<6 \mathrm{kHz}$, any oxide layer formed at $E_{\mathrm{u}}$ becomes compleiely electroreduced at $E_{1}=0.05 \mathrm{~V}$, and then, the overall process behaves as if only platinum electrodissolution/electrodeposition processes took place in each RSWPS cycle at $E_{\mathrm{u}}$ and $E_{1}$, respectively. But for asymmetric RSWPS, particularly for large $\tau_{u} / \tau_{1}$ ratios, a significant amount of platinum oxide can be formed. In any case, the frequency of the periodic perturbing potential plays a fundamental role as it determines the average thickness of the pulsating diffusionboundary layer, either anodic, $\delta_{a}$, or cathodic, $\delta_{c}$, associated with the transport of $\mathrm{Pt}^{2+}$ species out from the electrode surface during $\tau_{u}$ or in the opposite direction during $\tau_{1}$ [22-24]. The values of both $\delta_{\mathrm{a}}$ and $\delta_{\mathrm{c}}$ depend directly on the square root of $\tau_{\mathrm{u}}$ and $\tau_{1}$, respectively, as well as on $N$, the number of cycles, although in this respect a stationary situation arises for $N \rightarrow \infty$ [24].

It is interesting to attempt to establish whether the Pt overlayer results primarily from ORC associated with either reaction (1) or reactions (2)-(4). It is clear that the maximum degree of development of (100)-type pco is obtained at any frequency higher than $0.1 \mathrm{kHz}$ in the vicinity of $\tau_{\mathrm{u}} / \tau_{1}=1$. This means that the pco depends mainly on the ORC related to reaction (1).

For low frequency symmetric RSWPS, that is, in the $0.1 \mathrm{kHz}$ range, the values of both $\delta_{\mathrm{a}}$ and $\delta_{\mathrm{c}}$ are of the order of $10^{-3} \mathrm{~cm}[5,24]$, the overall electrochemical process is diffusion controlled and dendritic metal overlayers exhibiting a large value of $R$ are obtained. For higher frequencies, that is, in the $1-6 \mathrm{kHz}$ range, both $\delta_{\mathrm{a}}$ and $\delta_{\mathrm{c}}$ decrease to values between $10^{-4}$ and $10^{-5} \mathrm{~cm} \mathrm{[5]} \mathrm{and} \mathrm{the} \mathrm{kinetics} \mathrm{of} \mathrm{the} \mathrm{overall}$ processes change progressively from diffusion to activation control. Then, the 
electrodissolution/electrodeposition processes occur selectively since they become strongly dependent on the physicochemical characteristics of each crystal face [25], namely work function, potential of zero charge, anion adsorbability and surface hydrophobicity. Under these conditions, the morphology of the treated surface changes gradually to that of a faceted surface with development of pco.

For the particular situation found at $0.1 \mathrm{kHz}$ involving $\tau_{\mathrm{u}} / \tau_{1}$ ratios of 0.03 $\left(\tau_{\mathrm{u}}=0.3 \mathrm{~ms}\right)$ and $19\left(\tau_{1}=0.5 \mathrm{~ms}\right)$ corresponding to points $\mathrm{D}$ and $\mathrm{E}$ of Fig. 1a, the same kinetic explanation applies. In both cases, the kinetics of the overall reaction are largely determined by the shortest half-period. Therefore, under these conditions $\left(\delta_{\mathrm{a}}\right.$ or $\delta_{\mathrm{c}}<10^{-4} \mathrm{~cm}$ ), despite the low frequency value, the reaction also becomes activation controlled and strongly dependent on the properties of each crystal face. Thus, facetted surfaces with pco are obtained.

On the other hand, the development of surface roughness is, at all frequencies, located at $\tau_{u} / \tau_{1}$ values greater than 1 , that is, at a net predominance of $\tau_{u}$ over $\tau_{1}$ (Fig. 1). This indicates that the development of surface roughness involves the electroreduction of an oxide layer accumulated on the electrode during the ORC. The $\tau_{u} / \tau_{1}$ ratio associated with the peaked value of $R$ depends linearly on the period $(T)$ of the periodic perturbing potential (Fig. 2). Thus, for the higher frequencies, the peaked value of $R$ is approached for $\tau_{\mathrm{u}} / \tau_{1} \rightarrow 1$. It should be noted (Fig. 1) that for very large $\tau_{u} / \tau_{1}$ values, the increasing contribution of the ageing processes involving $O$-containing surface species hinders the oxide layer growth, and correspondingly, decreases the value of $R$.

As was discussed in previous papers $[3,5,18]$, the formation of thick platinum oxide layers under symmetric RSWPS can be interpreted in terms of a series of reversible reactions starting from the $\mathrm{Pt}(\mathrm{OH})_{\text {ad }}$ intermediate, finally yielding a non-aged hydrous metal oxide species. According to XPS data, this layer consists mainly of $\mathrm{Pt}(\mathrm{OH})_{4}$ species [26,27], although the existence of $\mathrm{Pt}(\mathrm{OH})_{6}^{2-}$ species has also been advanced [28,29]. For symmetric RSWPS, the short electroreduction half-cycle favours the advance in depth of the metal plane, maintaining continuously a fresh Pt surface and avoiding local acidification and water depletion at the metal/solution interface.

The characteristics of the platinum overlayer resulting from the electroreduction of the accumulated oxide layer depends on the properties of this layer as well as on the electroreduction procedure [30]. The latter aspects have been discussed recently for an accumulated oxide layer with exactly the same history [31]. In the present case, the thick oxide layer after proper electroreduction cycling at $0.1 \mathrm{~V} / \mathrm{s}$ between 0.05 and $1.50 \mathrm{~V}$ yields an electrodispersed metal layer consisting of a large number of nearly spherical sticking metal superclusters of ca. $10 \mathrm{~nm}$ average diameter (brush-like structure) as revealed by STM imaging [32].

\section{ACKNOWLEDGEMENTS}

This work was supported by the Universidad Nacional de La Plata, the Consejo Nacional de Investigaciones Cientificas y Técnicas, the Comision de Investigaciones 
Cientificas de la Provincia de Buenos Aires, the Organization of the American States and the Third World Academy of Sciences (TWAS). W.E. Triaca thanks TWAS for Research Grant No. 87-15.

\section{REFERENCES}

1 J.C. Canullo, W.E. Triaca and A.J. Arvia, J. Electroanal. Chem., 175 (1984) 377.

2 R. Cerviño, W.E. Triaca and A.J. Arvia, J. Electrochem. Soc., 132 (1985) 266.

3 A.J. Arvia, J.C. Canullo, E. Custidiano, C.L. Perdriel and W.E. Triaca, Electrochim. Acta, 31 (1986) 1359.

4 C.L. Perdriel, W.E. Triaca and A.J. Arvia, J. Electroanal. Chem., 205 (1986) 279.

5 A. Visintin, J.C. Canullo, W.E. Triaca and A.I. Arvia, J. Electroanal. Chem., 239 (1988) 67.

6 A. Visintin, W.E. Triaca and A.J. Arvia, J. Electroanal. Chem., 221 (1987) 239.

7 S.L. Marchiano, L. Rebollo Neira and A.J. Arvia, Electrochim. Acta, in press.

8 J.C. Canullo, W.E. Triaca and A.J. Arvia, J. Electroanal. Chem., 200 (1986) 397.

9 A.T. Hubbard, R.M. Ishikawa and J. Katekaru, J. Electroanal. Chem., 86 (1978) 271.

10 P.N. Ross, Jr., Surf. Sci., 102 (1981) 463.

11 J. Clavilier and D. Armand, J. Electroanal. Chem., 199 (1986) 187.

12 D. Aberdam, R. Durand, R. Faure and F. El-Omar, Surf. Sci., 171 (1986) 303.

13 J. Clavilier, R. Durand, G. Guinet and R. Faure, J. Electroanal. Chem., 127 (1981) 281.

14 C.L. Scortichini and C.N. Reilley, J. Electroanal. Chem., 139 (1982) 233.

15 F.T. Wagner and P.N. Ross, Ir., J. Flectroanal. Chem., 150 (1983) 141.

16 F.E. Woodard, C.L. Scortichini and C.N. Reilley, J. Electroanal. Chem., 151 (1983) 109.

17 W.E. Triaca, T. Kessler, J.C. Canullo and A.J. Arvia, J. Electrochem. Soc., 134 (1987) 1165.

18 A.C. Chialvo, W.E. Triaca and A.J. Arvia, J. Electroanal. Chem., 171 (1984) 303.

19 J. Clavilier, D. Armand, S.G. Sun and M. Petit, J. Electroanal. Chem., 205 (1986) 267.

20 A.V. Tripkovič and R.R. Adzić, J. Electroanal. Chem., 205 (1986) 335.

21 A.J. Bard, R. Parsons and J. Jordan (Eds.), Standard Potentials in Aqueous Solutions, Marcel Dekker, New York, 1985, p. 353.

22 A.R. Despic and K.I. Popov, J. Appl. Electrochem., 1 (1971) 275.

23 A.R. Despic in B.E. Conway, J.O'M. Bockris, E. Yeager, S.U.M. Khan and R.E. White (Eds.), Comprehensive Treative of Electrochemistry, Vol. 7, Plenum Press, Ncw York, 1983, p. 451.

24 C. Elsner, S.L. Marchiano and A.J. Arvia, Electrochim. Acta, submitted.

25 E.B. Budevski in ref. 23, p. 399.

26 M. Peuckert, Electrochim. Acta, 29 (1984) 1315.

27 E. Rach and J. Heitbaum, Electrochim. Acta, 31 (1986) 477.

28 L.D. Burke and M.E.G. Lyons in R.E. White, J.O'M. Bockris and B.E. Conway (Eds.), Modem Aspects of Electrochemistry, Vol. 18, Plenum Press, New York, 1986, p. 169.

29 L.D. Burke, M.B.C. Roche and W.A. O'Leary, J. Appl. Electrochem., 18 (1988) 781.

30 R. Salvarezza, W.E. Triaca and A.J. Arvia, Electrochim. Acta, in press.

31 E.V. Albano, H.O. Martin, R.C. Salvarezza, M.E. Vela and A.J. Arvia, J. Electrochern. Soc., in press.

32 L. Vásquez, J. Gómez, A.M. Baró, N. García, M.L. Marcos, J. González-Velasco, J.M. Vara, A.J. Arvia, J. Presa, A. García and M. Aguilar, J. Am. Chem. Soc., 109 (1987) 1730. 